Iman El Sayed Raslan

\title{
Paratextual and Intratextual Framings in Amy Tan's Saving Fish from Drowning
}

\author{
Iman EI Sayed Raslan
}

\author{
Helwan University
}

\begin{abstract}
Framing theory has been a field of interest in various areas of study. It has begun in sociology and entered the field of literature recently to help in the interpretation of fiction. The aim of this research paper is to apply frame theory to Amy Tan's Saving Fish from Drowning (2005) using Werner Wolf literary frame theories. The concepts of 'frame', 'framing' and 'reframing' will be explored and applied to the novel. Moreover, Werner Wolf's aspects of Paratextual and Intratextual framings will be also examined. The functions of framings display how Tan frames her narrative to shape people's opinions and to influence their attitudes concerning certain debated issues. Tan deliberately employs frames in the structure of her novel to shape the readers' opinions concerning oppression in Burma. She draws the reader's attention to the misconceptions that global media spreads about Burma.
\end{abstract}

Key Words: Framing theory, Saving Fish from Drowning, Paratexts, Intratexts, Burma.

Since the mid-1960s, framing theory has been a field of interest in various areas of study. It has begun in sociology and entered the field of literature recently to help in the interpretation of fiction. Werner Wolf maintains: "It has become a received notion that there is no human signifying act, no meaningful perception, cognition and communication without 'frames' and that frames are practically everywhere" (2006: 1).

This paper applies frame theory to Amy Tan's Saving Fish from Drowning (2005) using Werner Wolf literary frame theory. The concepts of 'frame', 'framing' and 'reframing' will be explored and applied to the novel. Moreover, Werner Wolf's aspects of "Paratextual" and "Intratextual" framings in fiction will also be tackled in the novel. Tan's novel lends itself readily to framing analysis, as she almost consciously employs different framings. Tan frames her narrative to shape people's opinion and to influence their attitudes concerning certain debated issues. Tan deliberately employs certain frames in the structure of her novel to shape the readers' opinions concerning oppression in Burma. Tan's novel proves her awareness of the influence of frames in shaping the human 
experience. The novel can serve as an exemplary text within the ChineseAmerican cultural context to examine the features of framing theory.

Frame theory originates in sociology and then transfers to the linguistic field and finally applies to media studies. Thus it is an interdisciplinary approach used to analyze the narrative form according to media politics. Framing theory was first introduced in Frame Analysis (1974) in which the socialist Erving Goffman presents the concept of frames as follows:

When an individual in our Western society recognizes a particular event, he tends, whatever else he does, to imply in this response (and in effect employ) one or more frameworks or Schemata of interpretation... [which] is seen as rendering what would otherwise be a meaningless aspect of the scene into something that is meaningful (21).

In other words, frames are used by people to interpret different life experiences. Frames help people to perceive the events and to deduce the reality behind them. The same event or 'strip' of experience can have different frames. Goffman insists that people interpret what is going on around them through their primary frameworks which are socially constructed due to the goals and manipulations of people. He maintains: "Each primary framework allows its user to locate, perceive, identify and label a seemingly infinite number of concrete occurrences defined in its terms" (21).

According to Goffman there is a clear distinction within primary frameworks: natural and social. "Natural frameworks identify events as purely physical occurrences due to natural determinants. Versions of these natural frameworks are found in the physical and biological sciences" (1974: 22). As for social frameworks, they provide background understanding for the events that "incorporate the will, aim and controlling effort of an intelligence of human beings. Motive and intent are involved and their imputation helps select which of the various social frameworks of understanding is to be applied. Thus social frameworks deal with deeds not mere events" (1974: 23). In everyday life, these frameworks greatly influence people's opinions and attitudes towards current issues. 
William Gamson develops the concept of frame to be like a storyline or an unfolding narrative about an issue. He states: "A frame is a central organizing idea or story that provides meaning to events related to an issue" (1975: 603). Moreover, Todd Gitlin defines frames as "principles of selection, emphasis and presentation composed of little tacit theories about what exists, what happens and what matters" (1981: $6)$.

Framing theory has been widely used in many fields such as linguistics and communication. The famous linguist, Van Dijk, defines frames as "knowledge representations about the world which enables us to perform such basic cognitive acts as perception, action and language comprehension...It has been emphasized that a frame not only contains 'static' data but also 'dynamic' procedures, describing how to act in certain circumstances ('Semantic' 1977: 19). He also suggests a discursive structural frame analysis model which includes two main steps. First, the frame must be identified through identifying the main elements of the text and by considering the vantage or 'point of view' from which the speaker examines those elements ('Story' 1980: 3). Second, the elements of the texts have to be organized by the frame to perform four tasks of discursive structures. These tasks are, firstly, enabling the receiver to select some elements for interpretation and to delete others that are relevant to the message. Secondly, they enable receivers to organize the elements of the message hierarchally. Thirdly, they allow receivers to generalize the meaning of the message and finally enable receivers to derive a global fact from the message (News 1988: 156).

Furthermore, the linguist, George Lakoff, develops the term frame and defines it as "mental structures that shape the way we see the world" that "shape the goals we seek, the plans we make, the way we act and what counts as a good or a bad outcome of our actions" (2004: xv). However, he focusses on the impact of framing which "is critical because a frame once established in the mind of the reader (or listener, viewer, etc.) leads that person almost inevitably to the conclusion desired by the frame and it blocks consideration of other possible facts and interpretations" (Manifesto 2003: 3). He also thinks that once phrases become part of everyday language, their frames become fixed in people's minds. Therefore, once this occurs, more facts that don't fit the frame are 
ignored. He encourages the readers to resist frames and to be engaged in a process of 'reframing'. He maintains:

Reframing is changing the way the public sees the world. It is changing what counts as common sense. Because language activates frames, new language is required for new frames. Thinking differently requires speaking differently (Don't Think of an Elephant 2004: 6).

In the communication field and media studies, Robert Entman displays "how frames become embedded within and make themselves manifest in a text or how framing influence thinking" (1993: 51). Thus framing is considered a "deliberate, conscious process in a communicating text in such a way as to promote a particular problem definition, casual interpretation, moral evaluation and/or treatment recommendation for the item described (1993: 52). Frames then define problems, diagnose causes, make moral judgments and suggest remedies (52). Entman asserts also that frames focus on certain issues in order to make them noticeable and memorable to readers.

Entman is the one who brings frame analysis to the literary field. He asserts that applying framing theory in the analysis of literary works "illuminates the precise way in which influence over a human conscious is extended by the transfer (or communication) of information from one location such as speech, utterance, news report or novel, to that consciousness (1993: 53). Similarly, Werner Wolf points out the importance of framing theory in the interpretation of literature. Wolf defines frames as "basic orientational aids that help us to navigate through our experiential universe, inform our cognitive activities and generally function as preconditions of interpretation" (2006: 5). As a result, frames are considered "meta-communicative concepts" or "cognitive guides of interpretation that are cultural constructs and hence have a certain historical and cultural flexibility according to different cultures and periods" (2006: 4). In this sense, frames are keys to abstract knowledge and to the understanding of literature and other media. As frame is considered an abstract cognitive notion, framing is defined by Wolf as:

Codings of abstract cognitive frames that exist or are formed within, or on the margins and in the immediate context of, the 
framed situation or phenomenon and -like the corresponding frames- have an interpretative, guiding and controlling function with reference to it. such coding can occur in an encoding activity of - in the terminology of communication theory- 'the sender', it can consist in a decoding activity of the 'recipient', or it can be part of the 'message' and its context (2006: 6-7).

In Tan's novel, frames exist on many levels. On the first level, it takes the form of frame story which is a story or narrative within another story or narrative. The outer narrative, the first narrative, frames the inner narrative. Frame narratives allow the inner stories to be told. Frame narrative is an example of what Wolf identifies as 'framing borders' for which he gives special importance as "it is at the beginning of an intended reception process that important frames of reference are traditionally signaled and exceptions are created" (Wolf 2006: 22).

In Framing Borders in Literature and Other Media Werner Wolf maintains that in printed literature textual framing may be divided into "Paratextual framing" and "Intratextual framing". Paratexts are parts of individual works and are positioned at their borders, but are discernible not only through their liminal position but also through their function as introductory, explanatory etc. material that forms a 'threshold' to the main text of the work in question. Paratexts are positioned in between text and context and belong to the work but not to the text proper. In printed literature, such 'Paratextual' framings include titles, epigraphs, footnotes, postscripts etc....[on the other hand], 'Intratextual' framings comprise all elements within the main text that signal particular cognitive frames which are relevant to the reception of the work in consideration (2006: 19-20).

Typical of Wolf's theory is Tan's use of the Paratexual framings in the form of the title of the novel, that of the chapters, the quotation of Camus as an epigraph to the novel and mainly the use of framing borders around the news report. Tan's novel follows the exact aspects of the literary frame. Using frames starts from the title of the novel which is ironic and paradoxical. The paradoxical nature of the title is the first frame that Tan uses in structuring her novel. It refers to a Buddhist myth about a pious fisherman who says that he takes fish from water to save them from drowning. But he is always late so the fish die when he brings 
them to land. As a result, he sells the fish in the market and uses the money to buy more nets to save more fish.

According to Lo Lai it is difficult to realize the man's intention; is it to justify killing fish for profit or does he really believe that he is indeed saving fish from drowning as an act of kindness. Thus the reader has to delve deeply on the real significance of the good and the evil. Does it imply that human beings are good and virtuous simply because they are saving fish from drowning or does it mean that human beings are evil because they intentionally have to kill fish for the survival of the fittest and for maintaining people's lives? In Burma, the Buddhists believe that saving fish with the intention of saving them from drowning is humane. Human beings are forced to be compassionate towards other creatures. However, greediness and selfishness of people lie beneath saving fish (2015: 12). Lo Lai asserts that the title is considered "a satire by which Tan addresses the kernel of Burma" (2015: 13).

John Frow states that for the literary text, "the frame is very complex: it is made up, first of all, of the covers of a book; of the title pages and other special framing effects which may frame individual pages"(1982: 26). The title of Saving Fish from Drowning is illustrated by the design of the cover which reflects a fisherman standing on one foot on his boat while the other foot is holding a net in the water. Tan draws the reader's attention to the first frame that is going to be motivated in the mind of the readers through the title. Hence starting from the title of the novel, there is a deliberate idea of framing. Tan asserts that her goal in writing the novel is to lure the reader into Burma. In an interview she confirms:

I was always keeping in mind that I needed to lure the reader, in the way fiction can be seductive and subversive, to a place most of us don't want to go....Get people hooked into a story with whatever genre worked-romantic comedy, adventure, murdermystery.... and get them to this very dark place and simply get people to remember the country Burma, that's now called Myanmar, that there are people who are suffering and dying (2005: 1).

Tan uses the title of the novel again as the title of one of her chapters in the novel in which the American tourists wonder about the real 
significance of this Buddhist myth. Rupert, the youngest of the tourists, asks: "Can fish drown?" Harry Bailley, one of the American tourists, answers:

They can indeed drown. In humans who drown, the lungs fill with water, and because our lungs are incapable of filtering out usable oxygen, the person suffocates. That's the cause of death, lack of oxygen. We call it drowning, because it occurs in water or with some sort of liquid.... Fish, on the other hand, have gills that extract oxygen, but most fish have to keep moving about to bring in a lot of water to filter enough oxygen. If they were not able to move, say they were caught in a reef pocket at low tide, or stuck on hook, they would eventually suffer from oxygen deprivation and suffocate. They drown....Their gills are like two silky-thin arches. They're suspended wide open in water, like double sails on a boat. Out of water, the arches collapse like a plastic baggie and press against each other, sealing them off so no air gets in. The fish suffocate....They are drowning on land" (Saving 170-171).

The Buddhist myth is preceded by a quotation of Albert Camus as an epigraph of the novel which reads that "The evil that is in the world almost always comes of ignorance, and good intentions may do as much harm as malevolence if they lack understanding". Camus attempts to say that what appears to be good can be evil, whereas what appears to be intentionally good can be malevolent. Through these aspects of the literary frame, Tan motivates the cognitive framing in the minds of the readers.

The cognitive framing in the novel is multiple. The title, Camus's quotation and the Buddhist myth of the fisherman are reinforced by the boarder frame of a newspaper report in the San Francisco Chronicle that announces the missing of eleven American tourists in Burma. Tan starts her deliberate framing process through this newspaper report. She encloses it in three pages without any page numbering. It is very distinct because she frames it by framing borders to draw the attention of the reader to this literary frame that will motivate the cognitive framing in his mind. The news report regarding these missing tourists draws attention to the Intratextual framing which has been used by Tan in the prologue. Entman confirms that frames call attention to some aspects of reality 
while obscuring other elements, which might lead audiences to have different reactions" (1993: 55). The report is shown as follows:

Tourists Flee Burma,

Fears Over 11 Missing Americans

By May L. Brown

Special Field Report for the San Francisco Chronicle

MANDALAY, December 31-In the glossy, air-conditioned bar of the Golden Pagoda Hotel, pampered tourists escape the humidity with cocktails charged at upscale American prices. But none are celebrating the coming New Year in the wake of reports that 11 Americans on an art expedition in Burma have been missing for almost a week under "suspicious" circumstances. The jittery hotel guests exchange rumors ranging from drug-running and hostage-taking to revenge by disturbed Nats, mischievous spirits in Burmese superstition.

According to Wolf, Intratextual framings comprise all elements within the main text that signal distinguished cognitive frames which are relevant to the reception of the work in consideration (2006: 20). All kinds of framing occurring in real life will tackle those Intratextual framings that contribute to the coding of literary works. In Tan's Saving Fish from Drowning, the newspaper report of San Francisco Chronicle is considered an Intratextual framing to the whole novel. It includes simple information about the missing of the American tourists that may influence the reception of the reader towards their experience. Hence it will refer to some content details about the tourists' experience in Burma.

The reporter thinks that the tourists have been kidnapped by the gangs of the heroin trade. Some people in the hotel believe that the angry Nats (Spirits of Nature) have taken revenge from the tourists because some of them do not respect the Buddhist holy temples. Out of ignorance and cultural misunderstandings, Harry Bailley urinates in one of the Buddhist shrines because he imagines it to be a public urinal. Later, the reporter thinks that they have been kidnapped because one of them is a prominent journalist, Wendy, and an activist for a human rights organization, Free to Speak International. Wendy has written: 
stories about oppression, all of which are credible and well documented.... She has participated in rallies in support of Burma's opposition leader, Aung San Suu Kyi, "the lady," whose party's landslide victory in the 1990 elections was illegally overturned by the junta [military government]. The Lady who has been under house arrest since 1989, was awarded the Nobel Prize for 1991. She has repeatedly called upon other governments to apply pressure on the junta by ceasing commerce with Burma (News Report).

The cognitive framing of the novel is highlighted by this report. Through Saving Fish from Drowning Tan discusses the power of the global media and its influence on people's daily lives. Using the news report as a part of the literary frame, Tan "reels the reader" into her inner story of the tourists who disappeared. It is considered a bait through which she will introduce the reader into cognitive framing.

In his article "the Literary Frame" John Frow confirms that "the authority of the frame is equivalent to that of the genre expectations which it establishes, and the internal structure of the text may either confirm this authority or react dynamically to it" (1982: 27). The structure of the text is only made possible by the presence of this frame. Frow asserts: "every aesthetic object or process has a frame or frames peculiar to it. Since the frame is not simply a material fact, it can be multiple" (1982: 25).

This is clear when Tan begins Saving Fish from Drowning with "A Note to the Reader" in which she recounts her encounter with Karen Lundegaard, a medium who talks to ghosts and writes down their random thoughts. This process is called automatic writing. Thus the genre that establishes the frame is the ghost narrative. Karen's supernatural writing includes Bibi Chin's thoughts, which serve as the framework of the novel's plot. Bibi was planning an art trip to Myanmar, Burma, with twelve American friends before her mysterious death. Tan uses the ghost narrator as "a literary device to criticize cultural ignorance, calling for increased understanding and respect of each other's traditions and social customs" (Chla-Rong Wu in Tunc and Marino 2010: 26). Tan writes:

Whether one believes in communication with dead or not, readers are willing to suspend disbelief when immersed in fiction. We want 
to believe that the world we have entered through the portals of another's imagination indeed exists, that the narrator is or has been among us. And so I have written this story as that, fiction inspired by Karen Lundegaard's automatic writings (Saving Fish xiv).

Amy Tan narrates this part in a very realistic tone in order to convince the reader of the existence of 'automatic writing'. However, she asserts in an interview that "all of this is presented as if it were true, but it is not" (2005: 1). Bibi Chen recalls the incidents of her death and of her funeral through automatic writing. This is very imaginative because no one can tell what happens in the future after his death. Bibi dies unexpectedly just weeks before her trip to Myanmar. Being a ghost narrator, Bibi enables her readers to know her past life, present and future. Despite her death, Bibi's friends decide not to cancel the trip and hope that she would join them in spirit. The novel tackles the point that "the interpretation of human actions is clearly influenced by culture. This concept is reinforced by Bibi's description of the American tourists' misconduct during their Asian trip" (Chla-Rong Wu 2010: 26).

In Bai Park, Harry, one of the tourists, mistakes a shrine for a public urinal, thereby enraging the local Bai people. Rupert, an adolescent boy in the group of the American tourists, is mistaken for a deity because he shows magical card tricks to the local people. This leads to the kidnapping of the American tourists, except Harry, by the leader of the Karen tribe on a lake outing on Christmas day. They are taken to the jungle to a place called 'No Name Place' where the rebel tribe is waiting for the Reincarnated Younger White Brother, who will make them invisible and help them in restoring their lands.

Being an amateur magician, Rupert is mistakenly recognized as the Reincarnated Younger White Brother. Therefore, the American tourists have been kidnapped by the leader of the rebelling Karen tribe, Black Spot. They imagine that Rupert is the Younger White Brother (their name for Jesus) whom they have been waiting for a hundred years to save them from the governmental oppression of the SLORC, military local authorities. Rupert entertains some citizens with his magic card tricks. So they believe that Rupert is their savior. They believe that he can make them invisible and help them to leave the country undetected by the governmental soldiers. Ironically, the tourists do not realize that they are 
being captivated and trapped by the tribe. They imagine that going to the jungle is included in their touristic program. They think that it is a Christmas surprise from their tour guide, Walter, Maung Wa Sao, to meet him in the jungle. They reach No Name Place through a swinging bridge that can be easily detached from either side of the gorge that it spans. To keep the tourists from escaping, Black Spot detaches the bridge and declares that it has to be repaired. He wants to detain them until Rupert, the Reincarnated Younger Brother, make the tribe invisible to escape undetected from the military authorities.

Karen people believe in the Younger White Brother who "had been part of their mythology for hundreds of years.... They also believe that one day [he] would return with a copy of their 'Important writings' which recorded their glory and history. With this magic book, the Karen people are certain that they could restore their tribe's power" (Saving Fish: 283). The tribe is waiting for Him (The Lord of Nats) because he would make them invisible "with bodies that no bullets would pierce" (303). As a result, they would take back their lands, would live in peace and no one would ever try to harm them again because "if they did the Younger White Brother would unleash on them, all the Nats [Spirits of Nature]" (303).

Amy Tan chooses the largest country in Mainland Southeast Asia, Myanmar, formerly known as Burma, as her setting. Burma is an important touristic attraction in China. It contains most of the temples of Buddhism. When the American tourists arrive at Burma, they realize that freedom of speech is strictly forbidden. "Burma is politically a closed country" (Lo Lai, 19). The authorities do not want to show the foreigners the real situation there in order to keep the touristic attraction to their country. Therefore, journalists are prohibited from entering the country and are not welcomed to preserve the perfect image of a romantic holiday. Phil Gutman, the director of Free to Speak International tells Wendy:

Journalists were prohibited from visiting Burma. If caught rummaging around for antigovernment views, they and their informants would be arrested, possibly tortured, and made to disappear into the same void into which thousands had gone before them. Worse, the government there would deny that it detained any 
political prisoners. And there you would be, invisibly imprisoned, forgotten by a world that had secretly concluded you must have had some degree of guilt for getting yourself in such a jam (Saving Fish 48).

The American tourists are the first Westerns to cross the borders between Burma and China. The road had been rebuilt by the Karen tribe, which was powerful against the military regime. Bibi Chen narrates:

The tribe had fought hard and well, and the military government finally sought a truce so that they might negotiate like reasonable despots of the world. By and by the tribe signed off to a cease-fire in exchange for a nod to build a business empire, unobstructed by the government and unfettered by competition. The Burma Road and its toll-booths, the major airlines, and some of the hotels [the American tourists] would be staying in were under the control of this entrepreneurial tribe (Saving Fish 175).

Tan implies that crossing the borders to China is considered an act of transgression. The tourists will realize the real condition of the Burmese people during their journey. Beneath the beautiful sceneries, there lies poverty, child abuse, domestic violence, illegal drugs trade and political turmoil. AIDS is also widespread on the borders. As a result, the tourists realize that Burma is the land of illusion. Bibi narrates:

Miss Burma is now married to a lunatic despot who has changed her name to Mrs. Myanmar. She has gone to live in Oblivion, so no one knows where she is. The husband is vile and beats his wife. The children have been abused as well, and now they bear scars and are hiding in corners. Poor Miss Burma, the former beauty queen, she would be gorgeous still if it weren't for the gaunt limbs, the missing eye, the lips mumbling the same babble (Saving Fish 151-152).

Wolf emphasizes that the frame of a frame story "is a privileged place for the coding of cognitive frames, a place in which such codings can occur with particular density or saliency" (2006: 7). Robert Entman states this word means "making certain information more noticeable and more memorable to the readers. An increase in salience enhances the probability that receivers will perceive the information, discern meaning and thus process it, and store it in memory" (1993: 53). In this respect, 
framing is an encoding activity by which the sender, Amy Tan, confirms the deliverance of her message. As Tan is fully aware of the frame of reference of her readers she employs framing to encode alternate frames of reference through her narrative which could be accepted by her readers. These new coded cognitive frames "prime values differently establishing the salience of one over the other" (Sniderman 1991: 52) thus launching a process of "reframing" of the power of the global media on people. These new codes of cognitive frames initiate a process of 'reframing' concerning the misconceptions about the missing of the eleven American tourists. In this novel, Tan chooses to write about Burma hoping that this could save her readers from "drowning in the biased interpretations" (Chiang Hsin-chen 2008: 4) about Burma and the oppression people face from the local authorities.

In Saving Fish from Drowning the frame story is the myth of the Buddhist fisherman while the inner narrative is the story of the missing of the American tourists in Burma. Tan is fully aware of the impact of framing on the readers and "the title sequence which supplements and narrows down the predefinition of the kind of aesthetic space being presented" (Frow 1982: 26).

Werner Wolf asserts that framing in literature exists in various forms that he arranges typologically according to certain criteria as follows: The first criteria of the typology of framings refers to the framing 'agency', in which there are several potential agencies: the 'sender' (author), the 'recipient' (reader) and the 'message' (novel) and its context. Wolf confirms that sender and recipient-based framings are considered interpretive encoding and decoding activities while contextand message-or 'text-based' framings can be regarded as interpretive signals and hence givens. These contextual framings are given framings that occur in the cultural space 'outside' the work of art as the authorial comments while textual framings refer 'inside' as part of the text (2006: 16). Tan's narrative falls into textual framings because it depends on the relationship between the sender and the recipient grasping of the different frames that the author sends deliberately.

The second criterion, according to Wolf, is applicable to all framing agencies concerning the extension of a particular framing or framing activity; it may be relevant to an entire work in which it is called 
a total framing or only to a part of a work, in which it is called a partial framing (2006: 17). In the novel under study, framing is total because Tan, deliberately, uses Paratextual frames which motivate the cognitive framing in the mind of the reader for the sake of 'reframing' in tackling the oppression that the Karen tribe face in Burma.

As for the third criterion, according to Wolf, is restricted to contextual framings, as it manifests itself only in products: it is of particular importance from an intermedial perspective. It means that both the framing and framed can be homomedial, belong to the same media, or heteromedial, belong to different media (Wolf 2006: 18). In Tan's case both the framing and the framed are homomedial because it is a printed work of art without any pictures or paintings.

Concerning the fourth criterion, in Wolf's point of view, it refers to the original unity of composition between framed and framings: It is also restricted to textual and contextual framings: Both framing and framed can form an originally planned and authorized compositional unit, in this case framing is called intracompositional or authorized; yet framing can also be altered or added to the framed independently of an original design, in which case they are called extracompositional or unauthorized (2006: 18). In Saving Fish from Drowning the framing is added to the frame of the original text, hence it is called intracompositional or authorized because the Paratextual and Intratextual framings are deliberately designed by Tan. She gives the Intratextual framing, the news report, salience by putting it inside frame borders.

Finally, according to Wolf, the fifth criterion that distinguishes between the different framings, is based on saliency. Either framings are salient, overt or explicit, or non-salient, covert or implicit. An overt or explicit framing is a discrete physical unit marking a frame in an easy way inside or outside the framed (part of a) work. It is easily discernible because it is located on a different level from that of the framed. Covert or implicit framing is also discrete physical marking of a frame, not easily discernible because it does not openly appear on another level from the framed. In Tan's text, the framing is overt or explicit because the incidents of the story where framing takes place is in a remote place in the jungle called No Name Place. 
As a Chinese American, Tan employs 'Reframing' to save her readers from disillusionment concerning the situation in Burma. She wants her readers to notice and understand the real predicament of the Burmese people. She is a humanitarian who wants to call for their human rights. What really happens to the Burmese people is horrible. When Roxanne, one of the American tourists, records some of the images that reflect the governmental oppression of the Karen tribe, she murmured:

What in God's name had happened to these people? There were two men, two women, and a pretty girl no older than ten. Each was missing a foot, or an arm, or the lower part of a leg, the limb ending abruptly in a coral cluster of blasted flesh. Why were they so horribly mutilated? Had they been in a bus accident? (Saving Fish 298).

The Karen people are once working for SLORC army. Their job is to step on land mines. When the mine is exploded, they lost some of their limbs. The soldiers become happy because the path is safe for walking. Therefore, the Karen tribe escapes to the jungle to hide from the SLORC soldiers who consider them like goats, animals that have to be hunted and slaughtered. "They would keep hunting them until a SLORC leader's dream had come true: that the only Karen you could see in Burma was stuffed in the glass case of a museum" (Saving Fish 324).

Reframing is closely attached to the function of frames. According to Wolf, the "message or text-centered" function is the most obvious since it may "be attributed to all elements providing a direct interpretive help for, or a control of, the reception by commenting on the 'text' or artefact and by creating certain expectations about it" (2006: 27). Framing manifests itself where certain elements are highlighted as meaningful or where a selection is prestructured. This function is present in all parts of the work of art giving information (Wolf 2006: 27). Another function is the "sender-centered" one which wolf explains as "the interpretive link, established by a framing between the artefact and its 'sender' and/or suggestion of his or her presence in the discursive exchange with the recipient. This function is related to the intention of the sender in sending a certain message (2006:30). Tan's assumed intention in sending her message through reframing is to warn people against misconceptions of certain issues. In Saving Fish from Drowning, Burma seems to be the 
heart of darkness and the land of illusion (Lo Lai 2015: 17). Everything that seems real turns to be an illusion. The reporter of the news report claims things that are totally untrue and the truth is revealed through the incidents of the jungle. Following the tourists deep into the jungle, Tan gives an account of the human treatment of the Karen tribe to the tourists. Thus, she starts the deliberate reframing process.

Framing in Saving Fish from Drowning is sender-based since Tan is consciously involved in a process of encoding. She employs the text as an effective tool to deliver her message so it is also text-centered. It has a recipient-centered function because it helps and controls the comprehension process. Tan's novel is divided into three stages of the framing process: the Paratextual frame of the first part that includes the title, the quotation of Albert Camus, the Buddhist myth of the fisherman and the Intratextual frame of the news report. All these literary frames instigate the cognitive frame in the mind of the reader in order to be able to grasp Tan's message through reframing.

Tan's real message is to attack global media that misleads the audience by biased news. Media people "call attention to particular aspects of the reality described, which logically means that frames simultaneously direct attention away from other aspects (Entman 1993: 54). In Tan's novel, the local authorities of Burma exploit the mystery of the American Tourists for its sake by filming a T.V. show called Mystery in Myanmar. The SLORC army knows that people rely on media to understand the world. Consequently, the Burmese government invites Harry Bailley, the American tourist who is left in the hotel, to host this T.V. show in order to broadcast the incident of his friends kidnapping and helps to rescue them. Harry imagines that this investigative documentary film will arouse people's attention towards this incident so they can help him in finding them. Thus "global media is considered as the saver" (Chiang Hsin-chen 2008: 7). Ironically, Harry is being manipulated and exploited by the Burmese local T.V. Company to promote its local tourism by inserting Burmese natural beauty and exotic culture into the show which aims to entertain Western people. Chiang Hsin-chen asserts: "the broadcasting of global media imposes on its audience a taste of exotic culture which, in part, leads to the flourishing of transnational tourism" (2008: 6). The show leads to the increase of the number of 
tourists to Burma and hence to the increase of the national income of the government. As a result, the show becomes "the best reality show around" (Saving Fish 410) although it does not help in finding Harry's American friends.

Meanwhile, the Burmese government issues a statement concerning the kidnapping crisis that reflects the Burmese government's power in manipulating global media. It makes use of Harry Bailley by misleading him into endless search for his friends following all the touristic places they visited in order to activate its touristic industry. The statement is full of lies to pacify the American public opinion. The statement is broadcasted as follows:

The State Peace and Development Council of Myanmar is concerned that other nations have been given incorrect information. We do not persecute any ethnic minorities. We welcome and treasure diversity of all people, including tourists. Even with tribes that have created unrest and unstable conditions, we have offered truces and signed peace agreements. We have several tribal leaders who can testify to this.... Unfortunately, some tribes in the hills have not heard of these truces....Some of these people did step on land mines, it is true, not as part of any jobs forced on them, but because they trespassed into restricted areas with mines planted by other ethnic hill tribes years ago, may be even their own. In the interest of safety to our people, we closed off those areas and marked them with big danger signs.... So we give our heartfelt sympathy that they were wounded. And if these Karen people come to our new modern hospitals, they will receive free care, even though it was their fault for trespassing and injuring themselves (Saving Fish 445).

The statement guarantees the safety and freedom of the Karen tribe and the Americans who are with them. The authorities offer the American tourists "a special getaway package to Bagan to visit its two thousand two hundred monuments" (Saving Fish 446). The tourists are rescued by a helicopter generously supplied by the Indian government. After their arrival to the States, they decide to meet for a "Celebration of Life" once a month, in addition to the annual Thanksgiving reunion. They return back home "more humane and less stereotypical, changing as a result of 
their experiences in the jungle" (Sandy Freund 2006: 158). Rupert gets fantasized about the Younger White Brother and the Lord of Nats myth. He plays an anime version of himself in these two roles. He practices new card tricks and surfs the Internet to know more about the Karen tribe.

As for the Karen tribe, the military government mentions in the statement that they will give them "their own land, the place where they are now, and the outlying areas of that, up to ten thousand acres" (Saving Fish 446) to do whatever they like concerning clearing the rain forest and planting crops and selling the teak wood.

What really offered to the Karen tribe is a reality show called Junglemanics! This show proves the government's manipulation of global media because what really matters for the authorities is transnational tourism. The show "captures the excitement of watching the real perils of real contestants in a real jungle, where elimination by real and excruciating death was always a possibility and might even occur live during broadcast" (Saving Fish 451). The tribe members are told they will receive a generous share of the profits on the "back end" with "points over net". The T.V. ratings went sky-high in just the first two weeks. It becomes number one among reality shows airing in the United Sates on Thursday during prime time.

Junglemanics! lasts high for a while especially when two of the American tourists after returning to America speak of the discovery of some jungle plants that have curable effects on malaria and others that have an aphrodisiac effect. The discovery of Balanophora, an aphrodisiac plant, led the military government to

rape the hills until there was hardly a tendril of Balanophora remaining. The military's consumption of the plant led to a resumption of rape of ethnic tribal women, while some military leaders justified as a natural way to assimilate tribes, for who could wage civil war with a new generation of mixed-blood babies? (Saving Fish 454).

Consequently, the Burmese government, the Junta, declares the destruction of the plant's habitat a "mismanagement situation requiring intervention" (Saving Fish 454). As a result, it takes control of the land. Junglemaniacs! was no longer prime-time but relegated to the less popular Sunday morning slot. Then the government declares that the 


\section{Iman El Sayed Raslan}

Karen tribe had never really owned the land because there was no private land ownership. The Junta has to step in and protect its assets. As a result, the show cancelled and the tribe never earns a single red cent.

Tan shows how global media exploits the Karen people and leads to their death in a refugee camp on the Thai border during their escape from the military soldiers. They are being drowned by the soldiers in a swollen river. Ironically, the Karen tribe take global media as their rescuer and expect that the shooting of the T.V. show would enable them to start a new life and to enjoy eternal safety. In the last chapter of the novel "The Nature of Happy Endings" Tan portrays the death of the Karen tribe after being shocked by the powerful influence of global media. Their temporary appearance in the Junglemaniacs! "accelerates their death" because the public loses interest in the show and its rating drops to the bottom. As global media abandons them, the tribe becomes under the control of the SLORC again. When the news of their deaths reach the American tourists, they become very sad and devastated.

The miserable fate of the Karen tribe displays that they are the victims of global media and governmental oppression. Global media is their real killer because it participates in destroying their natural environment in the jungle. Tan's framing process is revealed through reframing in which she gives "salience to the exiguities" in Burmese culture by selecting and highlighting some features of the culture while omitting others. Edelman focuses on the way frames exert power through the selective description and omission of the features of a certain situation:

The character, causes and consequences of any phenomenon become radically different as changes are made in what is prominently displayed, what is repressed and especially in how observations are classified...the world is...a kaleidoscope of potential realities, any of which can be readily evoked by altering the ways in which observations are framed and categorized (1993: 232).

Robert Entman asserts that the function of framing includes "selection and highlighting and the use of the highlighted elements to construct an argument about problems and their causation, evaluation and/or solution (1993: 52). By highlighting the oppression and suffering 
of the Karen tribe in Burma, Tan's 'framing' paves the way for her recipients to evaluate and change the frames they have about Burma. Tan's narrative gives new insights into the real reason for the atrocities of the ethnic minorities there. She draws the world's attention into the domestic violence and oppression of the Karen tribe in their own lands. Moreover, she gives voice to those silent people to allow her recipients to have another frame of reference to rely on instead of the stereotypical frames created by global media. In other words, Tan is involved in a process of reframing by creating a "new language" that is necessary for the formation of 'new frames'. In Don't Think of an Elephant Lakoff states that the basic principle of framing is that "when you are arguing against the other side: Do not use their language. [It] picks out a frameand it won't be the frame you want" (2004: 9).

Tan succeeds in disrupting the cognitive frames of her readers and in reframing or providing them with new frames that will help them in taking the action required. This is done only when she engages the reader in a journey to the Burmese jungle to perceive the real situation of the Karen tribe and the oppression they face from the military government. Her real message is that reality could be an illusion. It is only through the Paratextual and Intratextual framings of Wolf can she persuade the readers to join her in such insightful journey to save them from the misconceptions and misinterpretation of global media. 


\section{Iman El Sayed Raslan}

\section{Works Cited}

Van Dijk, T.A. (1977). "Semantic Macrostructures and Knowledge Frames in Discourse Comprehension". In M.Just and P.Carpenter (Eds.) Cognitive Process in Comprehension. Hillsdale, NJ: Lawrence Erlbaum Associates. . (1980). "Story Comprehension". Poetics. Vol. 9 : 1-3. . (1988). News as Discourse. Hillsdale, New Jersey: Erlbaum

Edelman, M.J. (1993). "Contestable Categories and Public Opinion” Political Communication 10 (3): 231-242.

Entman, Robert M. (1993). "Framing: Toward Clarification of a Fractured Paradigm". Journal of Communication 43(4): 51-58.

Frow, John. (1982). "The Literary Frame". The Journal of Aesthetic Education. University of Illinois Press. Vol.16 (2):25-30.

Freund, Sandy. (2006). "Amy Tan: Saving Fish from Drowning” The Book Review. School Library Journal. <www.slj.com>

Goffman, Erving. (1974). Frame Analysis: An Essay on the Organization of Experience. New York: Harper and Row.

Gamson, William A. (1975). "A Review of "Frame Analysis" by Erving Goffman" Contemporary Sociology 4: 603-607.

Gitlin, Todd. (1981). The Whole World is watching: Mass Media in the Making and Unmaking of the New Left. Berkeley, CA: University of California Press.

Hsin-chen, Chiang. (2008). "From an Ethnic Writer to a Global Writer: Amy Tan's Transition in Saving Fish from Drowning" Colloquium on Diaspora and Asian Fiction. National/Global Space.

Holland, Patrick and Graham Huggan (2000). Tourists with Typewriters: Critical Reflections in Contemporary Travel Writing. Michigan: University of Michigan Press.

"Interview: Amy Tan on 'Saving Fish from Drowning': A New Direction for Tan" in Weekend Edition. Sunday. Washington, D.C. (Nov. 20, 2005).

Lo Lai, CC. (2015) "Prologue-Life-Writing as a Journey to Myanmar (formerly) Burma". The Contour. Vol.1 (3): 7-31. <http://hdl.handle.net /10722 /225415>

Lakoff, George. (2003). George Lakoff Manifesto. $\langle$ http://www.infoamerica.org/teoria_textos/manifiesto_lakoff.pdf $>$. May 2017. . (2004). Don't Think of an Elephant: Know Your Values and Frame the Debate. Canada: Chelsea Green Publishing House. Print 
Sniderman, P.M., R.A. Brody and P.E.Tetlock (1991). Reasoning and Choice: Explorations in Political Psychology. Cambridge, England: Cambridge University Press.

Tunc, Tanfer Emin and Elisabetta Marino. Eds. (2010). Positioning the New Chinese American Literature and the Changing image of the American Literary Canon. London: Cambridge Scholars Publishing.

Wolf, Werner and Walter Bernhart. Eds. (2006). Framing Borders in Fiction and Other Media. New York: Ropodi. Print. 